\title{
Geomorfología aplicada a la evaluación de amenazas de origen natural en la zona sur de la comuna de Pichilemu, Región de O’Higgins, Chile.
}

\author{
Ignacio Ibarra Cofré1, ieibarra@uchilefau.cl; Carmen Paz Castro Correa²; María-Victoria \\ Soto $^{2}$; Rodrigo Rauld ${ }^{3}$
}

\section{RESUMEN}

Se analiza el área costera comprendida entre el headland de Punta de Lobos y la localidad de Cáhuil, en Chile central identificando las amenazas de origen natural y evaluando la susceptibilidad de ocurrencia de eventos hidrometeorológicos que generen inundaciones fluviales. Se analizaron los procesos morfodinámicos activos y factores condicionantes a través de cartografía geomorfológica, recolección de datos históricos, estadísticas pluviométricas, análisis hidrológicos y multitemporal de fotografías aéreas e imágenes satelitales. Los resultados obtenidos establecen que existen condiciones de amenaza (magnitud, recurrencia, alcance espacial), asociadas a procesos de remociones en masa, licuefacción y erosión de suelos, inundaciones fluviales, marejadas y tsunamis. La metodología fue validada con trabajo de terreno en los años 2013 y 2015.

Palabras clave: Geomorfología aplicada, procesos geomorfológicos, factores condicionantes, factores desencadenantes.

\section{Applied Geomorphology to assessment of natural hazards at the southern area of Pichilemu district, O'Higgins Region, Chile}

\begin{abstract}
Based on an applied geomorphology approach, the coastal area between Punta Lobos headland and Cáhuil locality (O’Higgins Region) was studied with the aim of identifying and characterizing natural hazards, and also for evaluating the specific susceptibility of hydrometeorological hazards occurrence related to fluvial and ponding floods. Morphodynamic processes and conditioning factors that contribute to generate geomorphological instability were analyzed through geomorphological, historical, hydrological, and multitemporal analysis of aerial photographs and satellite images. In addition rainfall statistics procedures were utilized. From the obtained results, it was determined that the study area presents different hazard conditions (magnitude, frequency, spatial extent) due to landslides, liquefaction and soil erosion processes, but also fluvial, ponding, tsunamis and storm surge floods.
\end{abstract}

Keywords: Applied geomorphology, geomorphological process, conditioning factors, triggering factors.

Recibido el 29 de abril de 2016; aceptado el 19 de julio de 2016.

Laboratorio de Geografía Física, Departamento de Geografía, Universidad de Chile, Portugal 084, Santiago, Chile.

2 Departamento de Geografía, Universidad de Chile, Chile.

3 Xterrae Geología, Chile. 


\section{INTRODUCCIÓN}

Si bien el riesgo natural es considerado un problema socio ambiental no resuelto (CARDONA 1999), la que constituyen un nuevo desafío en el estudio de los amenazas y riesgos naturales y la adaptación a los nuevos escenarios (LEI \& WANG 2014). En este contexto, se puede señalar que a nivel mundial en el periodo entre $1900 \mathrm{y}$ 2013, las inundaciones fluviales fueron el desastre natural más frecuente, afectando a más personas que cualquier otro evento de origen natural (BANKS et al. 2014).

Desde el punto de vista de los de diferentes tipos de amenazas, de escalas de análisis, de evaluación y de las condiciones de riesgos asociados, KAPPES et al. (2012) planteó el concepto de multiriesgos, asociado a los cambios ambientales y el impacto humano: este último como agente de cambio en los procesos y comportamiento de los sistemas morfológicos (KEILER et al. 2012). La literatura de las últimas décadas, coincide en señalar que factores asociados a procesos económicos, políticos y sociales, han producido un incremento de la vulnerabilidad a desastres (LAVELL \& FRANCO, 1996; BLAIKE et al. 2003; LAVELL 2004; PELLING 2003; D'ERCOLE et al. 2009; PELLING \& WISNER 2008, CASTRO et al. 2015). A través de elementos relacionados con procesos territoriales, tales como el uso, la ocupación y transformación del territorio a partir de la globalización económica, el incremento de la población, entre otros, el riesgo es una consecuencia de procesos económicos, sociales y políticos.

En estos escenario se debe considerar la mayor complejidad de los sistemas naturales y territoriales asociados a las intervención antrópica, propias de la época Antropoceno (WILCOX et al. 2011), y el desafío teórico es cómo enfrentar el crecimiento de los asentamientos poblados en el territorio. El crecimiento urbano hacia zonas con amenazas contribuye al aumento de la exposición y vulnerabilidad (SOTO \& MORENO 2012, SAHIN \& MOHAMED 2014, SOTO et al. 2015; CASTRO et al. 2015).

En Chile la actividad volcánica, terremotos $\mathrm{y}$ tsunamis, remociones en masa $\mathrm{e}$ inundaciones fluviales constituyen una condición de amenaza recurrente y de riesgo para la sociedad y la actividad productiva, generando grandes pérdidas económicas (SARMIENTO et al. 2015). Debido a la influencia de un margen de subducción activo, Chile tiene un alto y variado nivel de amenazas de origen natural, debido a una variedad de procesos geomorfológicos y geológicos. La exposición y el riesgo es además considerable puesto que muchas ciudades, algunas de ellas densamente pobladas, se localizan en zonas altamente peligrosas (CECIONI \& PINEDA 2010). En ese contexto, las ciudades costeras constituyen un escenario de alta vulnerabilidad debido a la ocurrencia de amenazas de origen marino y continental, originadas en procesos endógenos y exógenos.

En el litoral de Pichilemu el tsunami generado por el evento sísmico Mw 8.8 de 2010, se manifestó mediante el ingreso de tres frentes de onda, con una altura promedio estimada en $5 \mathrm{~m}$. El tercer frente fue el más destructivo, logrando afectar severamente la infraestructura próxima al borde costero (PUC 2010). Los efectos morfodinámicos fueron la erosión extrema de playas y dunas, dejando como rasgos geomorfológicos principales, perfiles de playas erosionales monosecuenciales, acantilados en cordones de dunas anteriores de hasta $4 \mathrm{~m}$ de altura y destrucción de barreras arenosas en lagoons (IBARRA 2014; SOTO et al. 2015). La deformación cosísmica inducida por el terremoto causó retroceso y subsidencia general de la línea de costa (QUEZADA et al. 2010).

El propósito de esta investigación es identificar y evaluar, bajo un enfoque 
geomorfológico aplicado, las amenazas de origen natural en la comuna de Pichilemu, específicamente en el área costera comprendida entre el headland de Punta de Lobos y el estuario de Cáhuil (Fig. 1). Se ha seleccionado el área de estudio debido a que el crecimiento urbano proyectado a partir del Plan Regulador Comunal (PRC) del año 2004, ha estado orientado al crecimiento hacia la consolidación de la conurbación de la ciudad de Pichilemu y la localidad de Cáhuil. El nuevo PRC finalizado el año 2012, permite la existencia de áreas sujetas a amenazas en zonas urbanas ya consolidadas (década del setenta), como también el futuro emplazamiento de residencias mixtas próximas al borde costero. Adicionalmente, el terremoto del 27 de febrero del 2010 (Mw 8.8), demostró la existencia de áreas expuestas a inundación por tsunami y licuefacción de suelos (SERNAGEOMIN 2010).

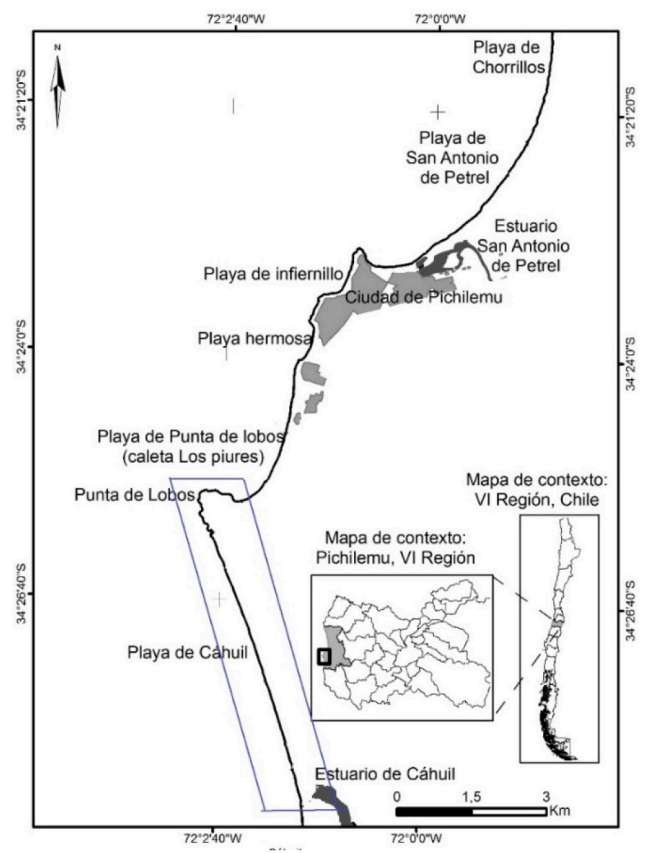

Fig. 1. Área de estudio.

Fig. 1. Study area.

\section{MATERIALES Y MÉTODOS}

\section{Análisis Geomorfológico y condición general de amenaza}

La metodología se estructuró en etapas, según se observa en la figura 2, a partir de métodos de mapeo geomorfológico, técnicas geomorfológicas de evaluación del terreno (FOOKES et al. 2007), en complemento con métodos históricos
(DÍEZ-HERRERO et al. 2008) y análisis estadístico de precipitaciones (GUMBEL 2004). Se obtuvo como resultado inicial la identificación y zonificación de las unidades morfodinámicas activas y episódicamente activas que se tradujeron en mapas de inventario y de zonificación de amenazas geomorfológicas.

Adoptando el enfoque metodológico de BRUNSDEN \& THORNES (1979), 
PANIZZA (1996) y FOOKES et al. (2007) formas activas, dinámicas o inestables son aquellas unidades y conjuntos morfológicos que están sujetos a constantes ajustes ante cambios en entradas y salidas de energía y/o de sedimentos en el sistema geomorfológico. Formas episódicamente activas son aquellas que presentan respuestas ocasionales ante eventos ambientales extremos. Formas activas como de actividad episódica tienden a constituir sistemas de respuesta rápida (sensibles) ante los efectos de la actividad humana o natural. Del mismo modo, formas relictas y que no se encuentran en evolución o morfogénesis actuales corresponden a formas inactivas toda vez que acciones antrópicas sin obras de mitigación contribuyan a desestabilizarlas.

Como resultado de lo anterior y en base a la metodología de PANIZZA (1972) y PEÑAMONNÉ (1997) se elaboró una matriz de unidades morfodinámicas en la que se integraron las unidades geomorfológicas, las causas de los procesos, es decir, los factores condicionantes, desencadenantes, el grado de actividad de estos eventos y las tipologías de amenazas identificadas (Tabla 1). Posteriormente se cuantificaron las áreas sujetas a procesos dinámicos, obteniendo valores de exposición a ellos. Lo anterior se realizó en el software ArcGis 10.1 mediante el cálculo automático del área abarcada por cada tipo de amenaza y de las áreas del Plan Regulador Comunal (PRC Pichilemu, 2012) destinadas a uso de suelo residencial y de equipamiento urbano. Las zonas bajo amenaza se intersectaron con los usos de suelos proyectados, obteniendo una estimación de superficies potencialmente expuestas.

Susceptibilidad de inundación asociada al drenaje del suelo

Mapa de inundaciones históricas o de inventario: elaborado en base a la fotointerpretación multitemporal de fotografías aéreas del Servicio Aerofotogramétrico de Chile (SAF) del año 1978, 1994 y 1997 (1:30.000; $1: 20.000 ; \quad 1: 30.000$, respectivamente); sets de imágenes Google Earth entre los años 2010 y 2015 y registros fotográficos históricos.

Mapa de unidades geomorfológicas: obtenido mediante mapeo morfológico de campo, descripción de cortes y trabajo de gabinete con curvas de nivel con equidistancia de $2 \mathrm{~m}$ superpuestas a los sets de fotografías aéreas e imágenes satelitales previamente descritos.

TABla 1. Matriz de Unidades MoRfodinámicas y AMENAZAS asOCIADAS.

TABle 1. Morphodynamic UNIT MATRIX AND HAZARDS.

\begin{tabular}{|c|c|c|}
\hline Unidad Geomorfológica & Condición de amenaza asociada & Grado de actividad \\
\hline Llanura aluvial & Anegamientos & Estacional \\
\hline Cárcavas y regueros & Erosión de suelos & Estacional \\
\hline Acantilados activos & Derrumbes & Activo \\
\hline $\begin{array}{c}\text { Escarpes de Terrazas } \\
\text { marinas }\end{array}$ & Derrumbes y deslizamientos & Latente \\
\hline Terraza marina baja & Tsunami & Latente / Estacional \\
\hline Terraza estuarial & $\begin{array}{c}\text { Tsunami, licuefacción de suelos, lateral } \\
\text { spreading / desborde de cauce }\end{array}$ & Latente / Estacional \\
\hline Playas arenosas & Tsunami / marejadas & Latente \\
\hline Campos dunares & Tsunami y licuefacción de suelos & \\
\hline
\end{tabular}


Mapa de coeficientes de escorrentía: obtenido mediante la integración de coberturas en formato shapefile de clases texturales y de drenaje de suelo proporcionadas por CIREN (1996, 2012), de fotointerpretación de usos de suelo en imágenes Google Earth del año 2010, además del valor de precipitación umbral de generación de anegamientos identificado durante el análisis estadístico de precipitaciones $(66 \mathrm{~mm} / 24 \mathrm{hrs})$, variables que luego fueron integradas mediante el método curva-número (S.C.S 1972).

Mapas de pendientes: se elaboró un Modelo Digital de Elevación del Terreno (MDT) construido en base a curvas de nivel de $1 \mathrm{~m}$, el cual fue reclasificado (Tabla 2) en base a los umbrales que relacionan procesos geomorfológicos y pendientes propuestos por ARAYA-VERGARA \& BORGEL (1972) y CIREN (1996).

Tabla 2. ReClasificaCión de PENDIENTES y SUSCEPTIBILIDAd DE INUNDACIÓN ASOCIADA.

TABLE 2. SLOPE REClasifiCATION AND FLOOD SUSCEPTIBILITY.

\begin{tabular}{|c|c|c|}
\hline Pendiente $\left({ }^{\circ}\right)$ & Tipo de terreno & $\begin{array}{l}\text { Susceptibilidad } \\
\text { inundaciones }\end{array}$ \\
\hline $0-1,04$ & Plano & Alta (1) \\
\hline $1,04-4,12$ & Ligera a suavemente inclinado & Media a baja (2) \\
\hline $4,14-81,9$ & Suavemente inclinado a muy escarpado o acantilado & Nula (3) \\
\hline
\end{tabular}

Coberturas rasters de flujos acumulados: Los terrenos más propensos de recibir flujos hídricos son un factor condicionante que ha sido propuesto para evaluar la amenaza de inundación asociado al mal drenaje de suelos por FEMA (2009) y DÍEZ-HERRERO (2008). La evaluación se realizó en el módulo Hidrology del software ArcGis 10.1 utilizando el MDT previamente descrito. Se obtuvo una cobertura raster con dos superficies: a) zonas con pixeles donde sí se acumulan flujos (1 o Verdadero); y b) zonas donde existe una ausencia de flujos acumulados $(0$ o Falso). Las primeras consideradas como áreas con niveles digitales indicativos de unidades del terreno propensos a recibir flujos hídricos en zonas deprimidas o llanas. Posteriormente, se elaboró una matriz de factores condicionantes adaptada de MARDONES \& VIDAL (2004) que fue integrada y ponderada en el software ArcGis a través del módulo álgebra de mapas raster. Se utilizaron tres grados nominales de susceptibilidad de inundación: alta, moderada a baja y nula, con peso 1,2 y 3 , respectivamente (Tabla 3 ).

La matriz fue evaluada en ArcGis 10.1 utilizando la herramienta Raster calculator. A cada variable se le asignaron distintos niveles de ponderación porcentual (máximo $100 \%=1.0$ ) aplicando la fórmula de susceptibilidad (1), en la cual se asignó mayor ponderación $(30 \%)$ a las unidades del terreno con evidencia de inundaciones históricas bajo la asunción que constituyen zonas con potencial para continuar inundándose al no existir aún medidas de mitigación; así como también a los grupos hidrológicos de suelo con sus respectivos coeficientes de escorrentía dado el control directo que ejercen las clases texturales de suelos que fueron identificadas en terreno (predominantemente arcillosas) en la capacidad de drenaje del mismo (JENN et al. 2007). Un $20 \%$ de ponderación fue asignada a la pendiente del terreno, 
TABla 3. Matriz de SUSCEPTIBILIDAd DE INUNDACión POR MAL DRENAJE DE SUELOS.

TABle 3. FloOd SUSCEPTIBILITY MATRIX FOR POOR SOIL DRAINAGE.

\begin{tabular}{|c|c|c|c|}
\hline $\begin{array}{c}\text { Variable/Grado de } \\
\text { susceptibilidad }\end{array}$ & Alta (1) & Moderada a baja (2) & Nula (3) \\
\hline Pendiente (') & $0-1,04$ & $1,04-4,12$ & $4,12-81,9$ \\
\hline $\begin{array}{c}\text { Grupos hidrológico de suelos/ } \\
\text { CE }\end{array}$ & $\mathrm{D}(0,47)$ & $\mathrm{C}(0,24-0,36)$ & $\mathrm{A}(0,15)$ \\
\hline $\begin{array}{c}\text { Pixeles con concentración de } \\
\text { flujos acumulados }\end{array}$ & 1 & 1 & 0 \\
\hline Zonas de amenaza declarada & 1 & 0 & 0 \\
\hline Unidades geomorfológicas & $\begin{array}{c}\text { Llanura aluvial y bordes de } \\
\text { lagunas costeras }\end{array}$ & Llanura aluvial & $\begin{array}{c}\text { Acumulaciones eólicas } \\
\text { indiferenciadas, dunas } \\
\text { rampantes, playas } \\
\text { arenosas, terraza marina } \\
\text { alta y remanente de } \\
\text { terraza marina }\end{array}$ \\
\hline CE: Coeficiente de escorrentía & Presencia : 1/ Ausencia: 0 & & \\
\hline
\end{tabular}

asumiendo su influencia directa en la capacidad de infiltración, dirección y aceleración del flujos (SOTO et al. 2010). $10 \%$ se asignó a las zonas con pixeles con flujos acumulados puesto que un $5 \%$ de la distribución espacial de dichos pixeles se encontró en unidades de ladera, lo cual sugiere mejoras en el Modelo de Elevación del Terreno utilizado y/o en los algoritmos de creación de flujos acumulados empleados. El mismo porcentaje fue asignado a las unidades geomorfológicas, dado que hasta dos variaciones de series de suelo (Curanipe 1-4 y Matanza 1-3) se localizaban en la misma unidad morfológica (Terraza marina), lo cual sugiere la delimitación específica y de detalle de unidades edafogeomorfológicas.

\section{(1)}

$A i=(P * 0.2)+(G H S * 0.3)+(F A * 0.1)+(Z I H * 0.3)+\left(U G^{*} 0.1\right)$

Donde: $\mathrm{Ai}=$ Susceptibilidad de inundación por mal drenaje de suelos; $\mathrm{P}=$ Pendiente; GHS = Grupos Hidrológicos de Suelos; FA = Flujos Acumulados; ZIH = Zonificación de Inundaciones Históricas o declaradas; UG = Unidades Geomorfológicas.

De acuerdo a la matriz y a la función de susceptibilidad, la delimitación de las zonas de amenaza quedó definida según los siguientes criterios:

Zonas de alta susceptibilidad (1): corresponden a aquellas áreas que de manera simultánea presentan pendientes menores a un grado; sumado a suelos del grupo hidrológico D (infiltración muy lenta y texturas finas) con coeficientes de escorrentía medio a alto; pixeles con presencia de flujos acumulados; además de ser zonas de anegamiento histórico; y morfología de llanura aluvial que constituye un relieve negativo (deprimido).

Zonas de susceptibilidad media a baja (2): corresponden a aquellas zonas que de manera conjunta presentan pendientes ligeras a suavemente inclinadas, además de suelos correspondientes al grupo hidrológico $\mathrm{C}$ (lenta infiltración y texturas finas), con coeficientes de escorrentía moderado a bajo, sumado a pixeles con concentración de flujos hídricos pero sin amenazas históricas, y morfología de llanura aluvial que constituye un relieve negativo (deprimido o plano).

Zonas de susceptibilidad nula (3): corresponden a aquellas áreas que en forma simultánea presentan pendientes 
suavemente inclinadas a escarpadas, sumado a suelos del grupo hidrológico A (alta infiltración y texturas gruesas), con coeficientes de escorrentía bajo, presentan ausencia de niveles digitales representativos de flujos acumulados, así como también de inundaciones históricas, y finalmente se emplazan en formas de relieve positivo, no expuesto a inundaciones.

Susceptibilidad de inundación fluvial en el curso inferior del Estero Nilahue

La evaluación de las áreas sujetas a inundación fluvial, se realizó en el curso inferior del Estero Nilahue (localidad de Cáhuil), mediante el análisis multitemporal de fotografías aéreas (SAF 1:20.000; 1:30.000 imágenes satelitales Google Earth $(2013,2015)$ y encuestas a la población, obteniéndose como producto un mapa de inventario con las cotas alcanzadas por las inundaciones históricas.

Se aplicaron métodos hidrometeorológicos para estimar caudales de crecida fluvial en el exutorio de la cuenca del Nilahue y sus períodos de retorno mediante el método de estimación de caudales instantáneos máximos (MOP-DGA, 1995) cuya modelación numérica se detalla en MOP-DGA (1995). Si bien ambos métodos consideran parámetros especiales de calibración en función de la realidad hídrica de las cuencas del país (razón por la cual fueron seleccionados), los caudales obtenidos se consideraron como indicativos, ya que dichos métodos no consideran pérdidas hídricas asociadas a las condiciones del sustrato/permeabilidad de las cuencas.

En trabajo de terreno, se construyeron dos perfiles topográficos de detalle representativos de la configuración hidrogeomorfológica del área de estudio. Siguiendo la metodología aplicada por GURNELL et al. (2003) basada en los resultados del mapa de inventario, ambos perfiles se realizaron en sectores donde hubo certeza de la cota alcanzada por inundaciones históricas. Frente a los sectores con control topográfico se procedió a medir la profundidad del curso fluvial a través de puntos de control previamente establecidos mediante GPS, con un distanciamiento promedio de 20 metros (transectas AA' y BB', figura 3). En cada punto se obtuvo la profundidad del cauce mediante una vara graduada.

Para estimar los caudales en las transectas AA' y BB', y de desbordes históricos, se aplicó la formula indirecta (2) propuesta de ARNAUD-FASSETTA et al. (2005); KNODEL et al. (2007) y WITHING (2003).

$$
\text { (2) }
$$

$$
Q=\left(0,921 \mathrm{n}^{-1}\right) \times A R^{0,67} \times S^{0,5}+2,362
$$

Donde: n: coeficiente de rugosidad de Manning; $A$ : área de la sección transversal del cauce $\left(\mathrm{m}^{2}\right)$; $R$ : radio hidráulico (m); $S$ : pendiente del lecho $\left(\mathrm{m} / \mathrm{m}^{-1}\right)$.

El valor de $S$ fue adquirido en base al estudio de ANDRADE \& GRAU (2005), quienes al medir las profundidades del lecho del estero Nilahue, calcularon una pendiente media en el trayecto inferior de 0,0004 $\left(\mathrm{m} / \mathrm{m}^{-1}\right)$. De ese estudio, se estableció además la presencia de barras subacuáticas efímeras y de generación estacional que contribuyen a incrementar la rugosidad del fondo del cauce, antecedentes que fueron considerados para la estimación del coeficiente de Manning. Dicho coeficiente se estableció en base a los parámetros de HERNÁNDEZ \& FRANCO (1999) y la observación tanto de las características del lecho como de la llanura inundable, por lo que se estimó un coeficiente de 0,082 como un valor adecuado. La obtención de $A$ y $R$ fue realizada en el software Autocad donde se estimó el área de la sección transversal y el perímetro mojado de los distintos puntos de interés, a través de los algoritmos de cálculo automático de perímetros y áreas que posee dicho software. 
Con lo anterior, se generaron curvas de descarga, y se estimaron las alturas de inundación sobre un MDT construido en base a curvas de nivel de $1 \mathrm{~m}$ de equidistancia. Finalmente, se utilizó el mapa de inundación generado mediante modelamiento hidráulico (PUC 2010), desarrollado en base al Hidrograma Unitario Sintético $S W M M$ y el software HECGEORAS, que permitió validar, corregir y mapear las áreas susceptibles a inundación previamente zonificadas mediante las curvas de descarga. Con los procedimientos anteriores, se identificaron tres niveles de susceptibilidad de inundación, delimitando las zonas de amenaza según los siguientes criterios:

Zonas de alta susceptibilidad: quedan delimitadas en base a las zonas de inundación histórica, y a las áreas que sean alcanzadas con caudales de períodos de retorno inferiores 10 años según la modelación hidráulica PUC (2010), y la estimación de caudales de crecida con sus correspondientes alturas proyectadas sobre el terreno y períodos de retorno desarrollado en el presente estudio. Complementariamente, bajo criterio geomorfológico, estas áreas corresponden a las zonas internas de la llanura costera (o terraza estuarial, Te) por presentar un relieve negativo.

Zonas de susceptibilidad moderada: quedan definidas en base a las áreas que no han presentado inundaciones históricas, pero presentan alcance de caudales asociados a períodos de retorno entre 20 y 50 años según la modelación hidráulica PUC (2010), y la estimación de caudales de crecida con sus correspondientes alturas proyectadas sobre el terreno y períodos de retorno desarrollados en el presente estudio. Conjuntamente, bajo criterio geomorfológico, estas áreas corresponden a la zona media de la llanura costera (Te) por presentar un relieve negativo.

Zonas de susceptibilidad baja: quedan definidas en base a las zonas cuyo período de retorno sea entre 50 y 100 años según el modelamiento PUC (2010) y la estimación de caudales de crecidas con sus alturas proyectadas sobre el terreno desarrolladas en el presente estudio. Complementariamente, bajo criterio geomorfológico, estas áreas corresponden a la zona de transición entre la zona externa de la llanura costera, la terraza marina baja y su escarpe.

Zonas de susceptibilidad nula: quedan definidas en base a las áreas correspondientes a la terraza marina baja y alta por ser en su mayoría morfologías de relieve positivo, fuera del alcance de inundaciones de los caudales de mayor período de retorno y su altura.

\section{RESULTADOS}

\section{Análisis Geomorfológico}

En la zona de Punta de Lobos y Cáhuil predominan playas arenosas, campos de dunas, lagunas litorales, escarpes y terrazas de abrasión marina, característico de los ambientes costeros de Chile central, fuertemente ligados en su condición dinámica a la ocurrencia de sistemas meteorológicos frontales y eventos sísmicos, inherentes a la región morfoclimática y morfoestructural (Fig. 3).

Al analizar los grupos de formas de la figura 3, destaca la presencia de la elevada terraza marina (40-50 m.s.n.m.) modelada en rocas metamórficas; el escarpe de esta terraza, es en general muy suavizado por el trabajo erosivo de laderas. En contacto con el escarpe se ha desarrollado un campo de dunas holocenas, de formas más bien indefinidas debido a los planes de manejo y control, estando en la actualidad bien estabilizado y muy vegetado, lo que impide la acción eólica. La herencia pleistocena de la terrazas marinas y el avance de las dunas, generó la formación de lagunas litorales entre ambas unidades, que son muy 


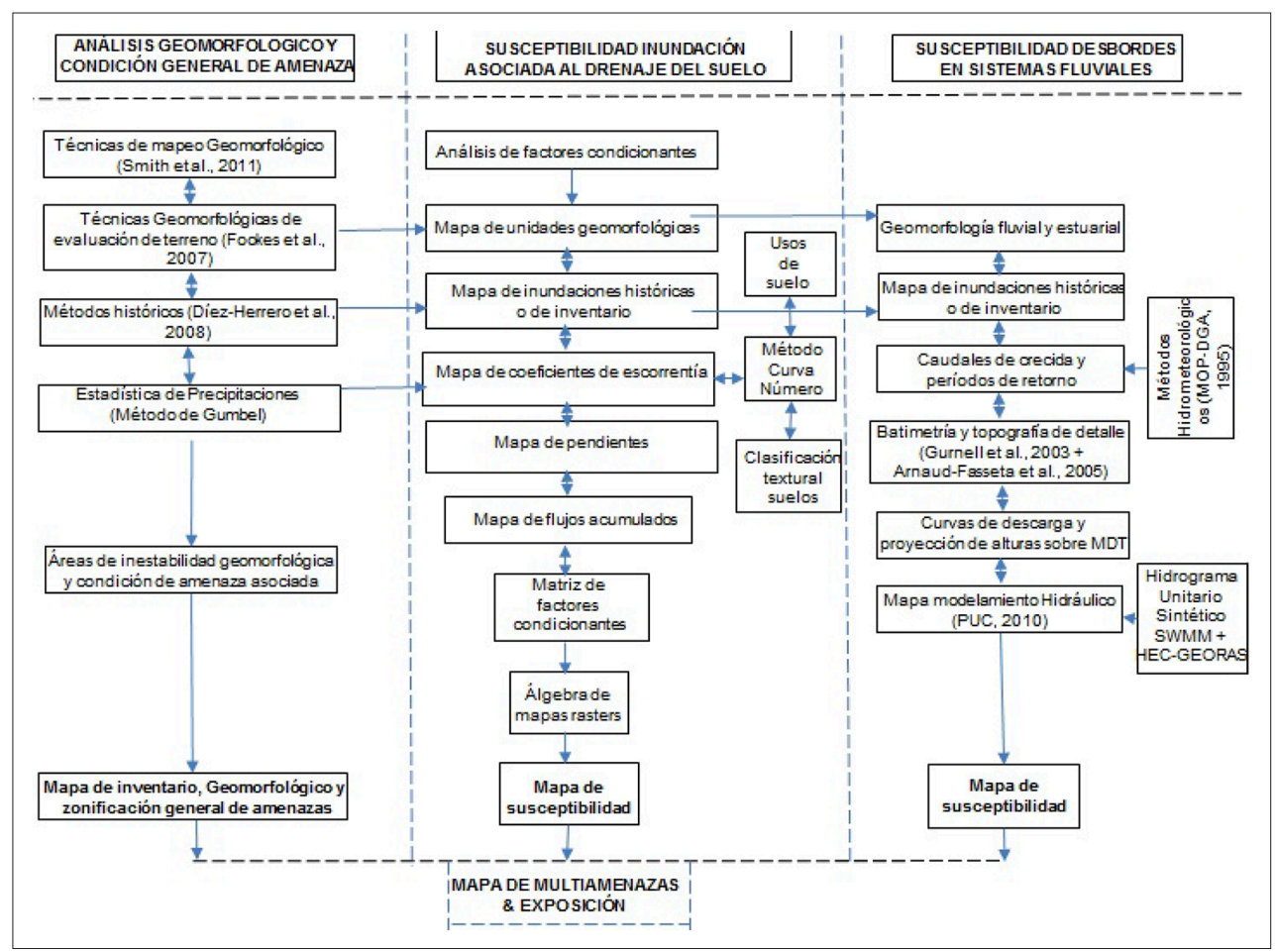

Fig. 2. Esquema metodológico.

Fig. 2. Methodological framework.

características en el áreas de estudio, debido a su valor en términos de biodiversidad y de paisaje. Estas lagunas no tienen relación funcional con la línea de costa actual y se activan sólo durante el invierno gracias a la acción pluvial. Presentan en consecuencia una marcada estacionalidad de tal manera que avanzan considerablemente en el período de máximas precipitaciones y el período de estío son áreas palustres.

En el área del estuario de Cahuil hay un cambio en la geomorfología debido a la condición de valle epigénico con terrazas de abrasión marina muy elevadas, del orden de los 100 m.s.n.m. y con escarpes muy marcados. En este valle la terraza marina baja está poco representada, debido a la geometría escarpada del mismo y la condición de ría, pero con la presencia de una terraza baja denominada por ARAYAVERGARA (2006) como terraza estuarial
(Te) de edad holocena, de baja altura (1m.s.n.m.), compuesta principalmente por arenas. El desarrollo de salinas en Cahuil se debe a la presencia de la Te y a la condición actuarial del estero Nilahue.

El litoral es predominantemente intermedio de alta energía, con rompientes de altura promedio de 2-3 m, que explica las condiciones de erosión de los perfiles de playas y de las dunas anteriores, no obstante el balance sedimentario es positivo y la playa no ha evidenciado condiciones de retroceso, incluso a pesar de la subsidencia cosísmica del 2010, debido al aporte sedimentario de la cuenca del Estero Nilahue, que se ve reflejado en una barrera litoral cerrada prácticamente durante todo el año. La permanencia del campo de dunas, activas pero estabilizadas por vegetación introducida da cuenta del aporte desde la cuenca. 


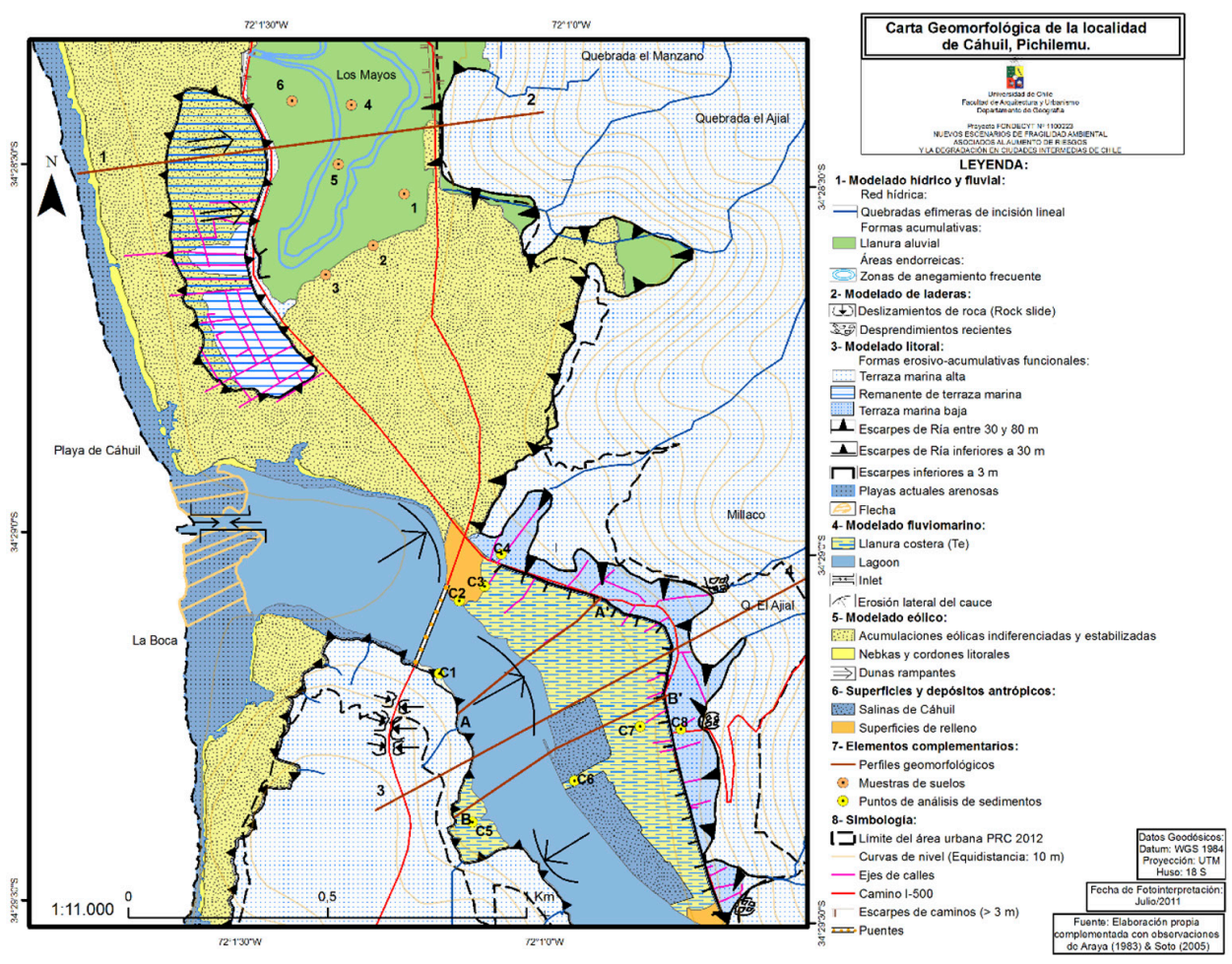

Fig. 3. Carta geomorfológica.

Fig. 3. Geomorphologic map.

Umbrales de precipitaciones

Los datos meteorológicos utilizados corresponden a las precipitaciones máximas anuales en 24 horas comprendidos entre los años 1980 y 2013, pertenecientes a la Dirección General de Aguas (DGA). Estos fueron registrados por la estación meteorológica de Pichilemu con datos de manera ininterrumpida desde el año 1980.

Con dicha serie se estimó el período de retorno de acuerdo al método de distribución de valores extremos de GUMBEL (2004) cuya ecuación fundamental es:

\section{(3)}

$$
F(x)=\exp (-\exp (-(x-u) / \alpha)))
$$

Donde los parámetros $u$ y $\alpha$ se calculan usando los datos de la muestra y se determinan usando las siguientes formulas (método de los momentos):
(4)

$$
u=\mathrm{x} 0.5772 \alpha \quad \alpha=\frac{\sqrt{6} S_{x}}{\pi}
$$

Donde: $\mathrm{x}=$ media muestral; $S_{x}=$ desviación típica muestral.

Relacionando los períodos de retorno obtenidos (Fig. 4) con los catastros históricos utilizados (fechas de fotografías aéreas, de imágenes satelitales y de registros fotográficos) se observa que el umbral a partir del cual se generan inundaciones por desborde fluvial, ocurre con $77 \mathrm{~mm}$ (26 de Mayo del 2012), y presenta un período de retorno (T) estimado en 10 años. Mientras que para el caso de las áreas susceptibles a inundarse por mal drenaje de suelos, este valor fue es ligeramente inferior, con un monto de precipitación de $65 \mathrm{~mm}$, el cual presenta un $\mathrm{T}$ de $\sim 5$ años. De acuerdo al rango y magnitudes de la serie de datos 
de Pichilemu, dichos eventos pueden considerarse de frecuencia baja a media, respectivamente, sin embargo de alta posibilidad de generar amenaza. Destaca un evento de magnitud $100 \mathrm{~mm} / 24 \mathrm{hrs}$ cuyo período de retorno es de 52 años, considerado un evento extremo.
Eventos entre 22 y $55 \mathrm{~mm}$ presentan bajos períodos de retorno (alta frecuencia) y bajo nivel de amenaza. Por otra parte, eventos entre 56 y $65 \mathrm{~mm}$ corresponden a eventos de mediana frecuencia y moderada amenaza para generar inundaciones asociadas al drenaje de los suelos

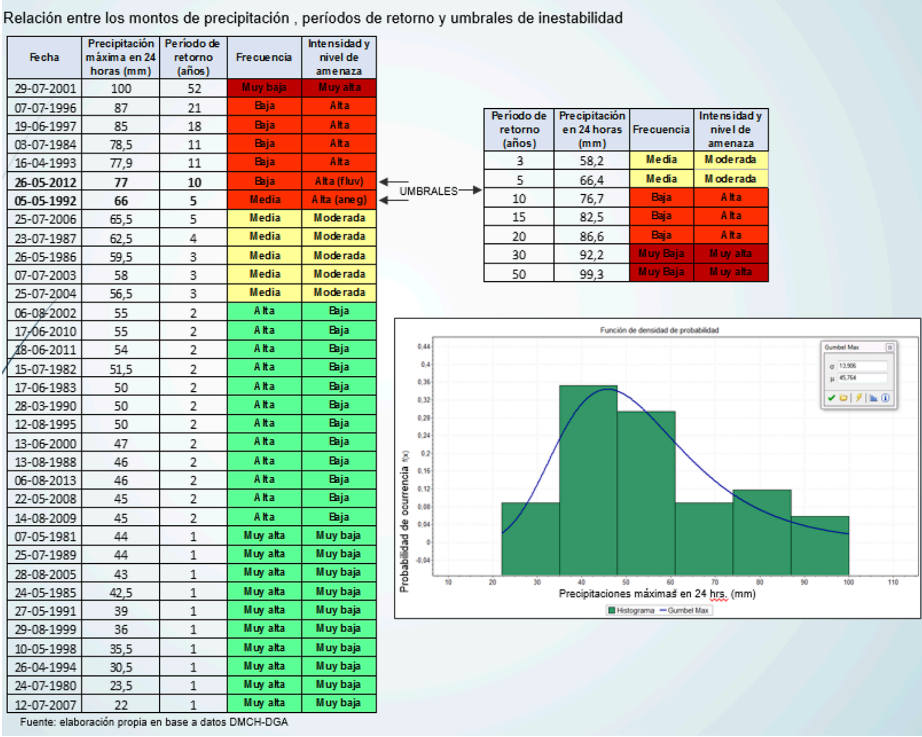

Fig. 4. Relación entre montos de precipitación, períodos de retorno y umbrales de desencadenamiento de amenazas hidrometeorológicas en el área de estudio.

Fig. 4. Relationship between precipitation, return period and hidrometeorological hazard triggering threshold in the sytudy area.

Amenazas de origen natural e impacto territorial

Las zonas de alta susceptibilidad de inundación por desborde de cauce se localizan en las riberas del estuario de Cáhuil (Tabla 1). La baja altura de la Terraza Estuarial $(0,2$ a $1,8 \mathrm{~m}$ sobre el estuario), su morfología llana, con buzamiento leve hacia el SW $\left(1^{\circ}\right.$ a $\left.2^{\circ}\right)$ y un nivel freático muy próximo a la superficie $(0,5$ a $3 \mathrm{~m}$ bajo el terreno) y que responde rápidamente ante las fluctuaciones de caudal, han permitido desbordes de hasta $140 \mathrm{~m}$ de extensión sobre dicha terraza, logrando inundar áreas residenciales (Fig. 5a). No obstante, la extensión de las zonas de inundación se encuentran fuertemente controlada por el escarpe que limita a la terraza estuarial de la terraza marina baja, cuya altura no supera los $3 \mathrm{~m}$ (Fig. 6). Bajo la nueva proyección del área urbana, un $4 \%$ se encuentra expuesta a esta amenaza, e incluye áreas de uso residencial y equipamiento urbano (Fig. 7).

Las áreas de inundación por mal drenaje de los suelos (Fig. 6), se encuentran en todas las zonas deprimidas entre el litoral de Punta de Lobos y Cáhuil, y su presencia se explica por el desarrollo de estrechas llanuras aluviales con suelos de textura arcillosa y de baja permeabilidad. Esta condición de amenaza 
se debe a que la escorrentía proveniente desde las laderas cercanas a transportando materiales coluviales finos mediante procesos de arroyada difusa, laminar y concentrada (sheet wash y rill wash), cuyos materiales altamente lixiviados se acumularon en fondos de valle. Sumado a esto, hacia el flanco poniente del litoral, el camino I-500 constituye una obstrucción topográfica de $2 \mathrm{~m}$ de altura, lo que se traduce en áreas típicamente endorreicas, y en consecuencia, frecuentemente inundadas (Fig. 5b). En los distintos sitios de muestreo, los análisis texturales del suelo indicaron la predominancia de arcillas, y el análisis de coloración Munsell, arrojó valores de 10 YR 3/1 (gris muy oscuro), lo que acusa una constante humectación del pedón y suelos frecuentemente humectados. Los porcentajes de exposición asociados a esta amenaza son de un $3 \%$.

Los procesos de inestabilidad de laderas identificados corresponden a derrumbes y deslizamientos, y se localizan en acantilados activos, en los escarpes interiores de las terrazas marinas, en la ruta I-500 e I-520 (Figs. 5c y 5d). En el área de estudio, éstas tipologías de movimientos en masa presentan tres factores condicionantes en común: a) pendientes mayores a $40^{\circ}$, superando ampliamente los umbrales morfológicos de estabilidad (SELBY 1993); b) litologías metamórficas muy meteorizadas, en afloramientos con múltiples planos de discontinuidad, que además de producir material poco consolidado, favorecen la absorción de agua durante eventos pluviométricos, saturando la roca y contribuyendo a disminuir la resistencia de los materiales; c), en algunos sectores, la disposición estructural de la roca es favorable a la pendiente, ya que la foliación de los esquistos presenta manteos preferenciales en la misma dirección que las pendientes de los taludes.

Las fuertes solicitaciones sísmicas generadas durante el terremoto del año 2010 (8.8 Mw), demostraron que la
Terraza Estuarial de Cáhuil es una unidad geomorfológica altamente inestable ante esta amenaza, debido a las múltiples grietas de licuefacción que presentó, junto a deformaciones del terreno tipo lateral spreading (Fig. 5e). Los principales factores condicionantes que explican tal condición de peligro en la localidad de Cáhuil son niveles freáticos someros, a los que sobreyacen depósitos granulares de relleno antrópico no cohesivos. Pese a lo anterior, importantes áreas de expansión urbana proyectada permiten la localización de viviendas y equipamientos sobre la Terraza Estuarial de Cáhuil (Fig. 7).

Los procesos de erosión de suelos se localizan sobre las terrazas marinas, en un patrón de distribución espacial disperso (Figs. 4 y 7), en su mayoría, fuera del área de expansión urbana proyectada $(3 \%$ de exposición). Morfológicamente se encuentran representados por cárcavas, regueros y mantos de erosión laminar y su distribución está controlada por la presencia de areniscas poco consolidadas, sobre suelos descubiertos en zonas de sobrepastoreo y restringidas a pendientes que oscilan entre $\operatorname{los} 10^{\circ}$ y $30^{\circ}$ (Fig. $5 f$ ).

Tras el terremoto y tsunami de 2010 se generó la carta de inundación por tsunami del área de estudio (PUC, 2010), en la cual se estima que la cota máxima de inundación esperable podría ser de 7 m.s.n.m. (Fig. 7). Del análisis espacial, se desprende que la máxima exposición está dada por la ocurrencia de tsunamis, ya que un $45 \%$ de las superficies destinadas a uso residencial y de equipamientos se encuentran en área de inundación.

Desde el punto de vista de la acción de los procesos analizados, las unidades geomorfológicas presentan actividad debido a la ocurrencia de eventos pluviométricos intensos y esporádicos, cuando se trata de la dinámica subaérea, como también a sismos de gran magnitud, evidenciado por los efectos de los terremotos de 1985 

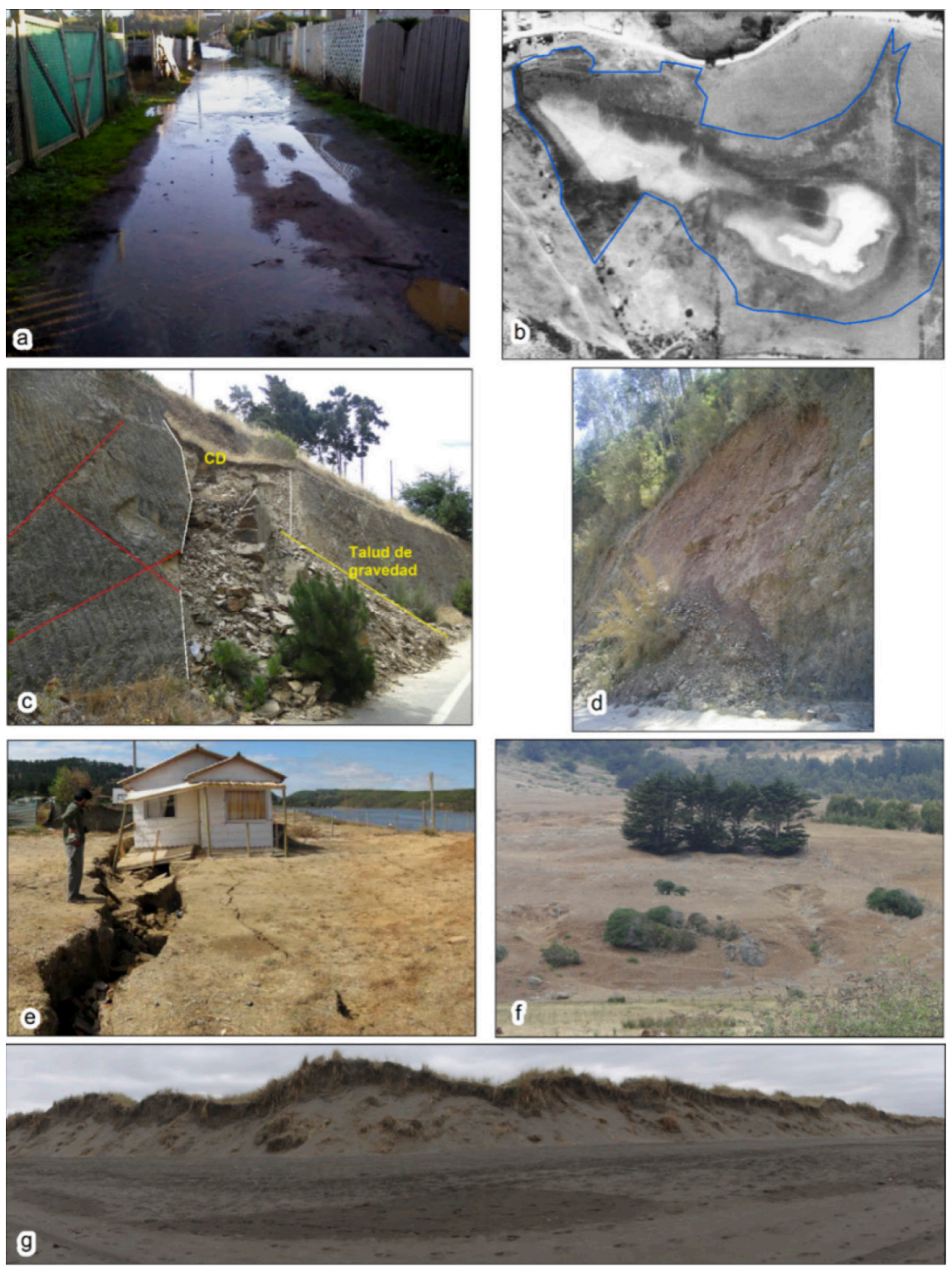

Fig. 5. Procesos geodinámicos: a) Cáhuil, inundación por desborde de cauce, debido a las intensas precipitaciones del año 2012; b) Cáhuil, inundación por mal drenaje del suelo, año 1994; c) Ruta I-500, derrumbes en rocas esquistosas altamente meteorizadas; d) Ruta I-520, deslizamiento traslacional de suelo; e) Cáhuil, licuefacción de suelos inducida por el terremoto del 27 de febrero del 2010; f) Punta de Lobos, cárcavas y erosión laminar del suelo; g) erosión y retroceso de playas y dunas luego del tsunami de 2010.

Fig. 5. Examples of landform processes and derivate hazards that take place in active geomorphological zones: a) Cáhuil, fluvial flooding triggered by heavy rains of 2012; b) Cáhuil, flooding due to poor drainage soils, year 2004; c) I-500 road, rockfalls developed in schist rocks highly weathered; d) I-520 road, single translational (planar) earth landslide; e) Cáhuil, soil liquefaction triggered by the 27th February, 2010 Earthquake; f) Punta de Lobos, gullies and sheet soil erosion; g) erosion and severe retreat of beaches and dunes after the tsunami triggered by the Earthquake of 2010. 


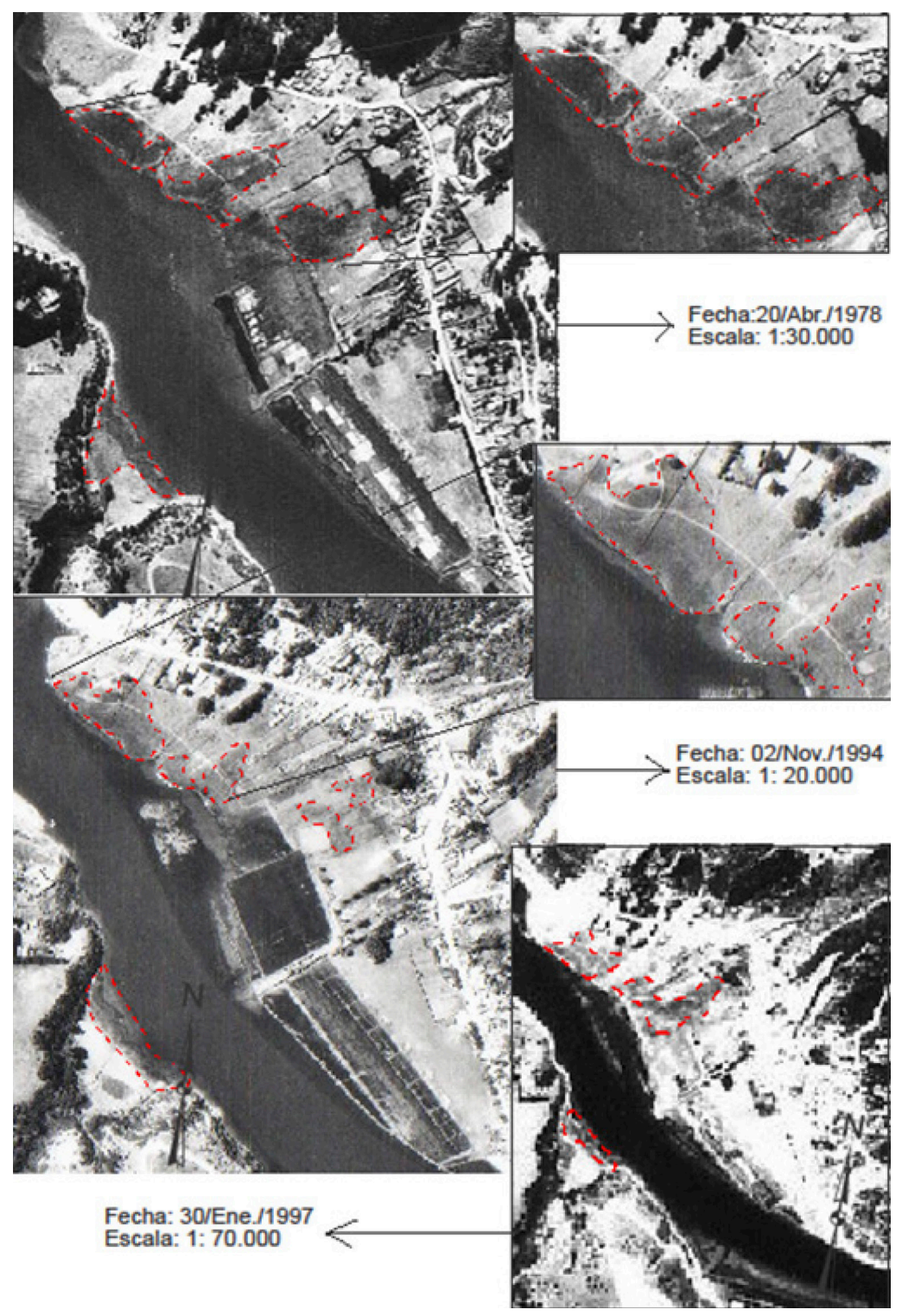

Fig. 6. Análisis multitemporal por desborde fluvial frente al pueblo de Cáhuil. La fotografía de 1978 corresponde a la fecha en que la condición de alta humedad del suelo se observa de manera más elocuente, toda vez que se detectan cuatro sectores con reflectancia muy oscura (líneas rojas segmentadas) levemente más claras que las del Estuario, representativos de una lámina delgada de agua o suelos altamente humectados. El ancho lateral máximo de esta condición de humedad alcanza aproximadamente los $110 \mathrm{~m}$ justo en el sector medio de la llanura costera (Te); mientras que el ancho mínimo alcanza los $\sim 40 \mathrm{~m}$ cercano a la zona del actual puente de Cáhuil. Similares patrones de reflectancia y textura se detectan en las fotografías aéreas de 1994 y 1997.

Fig. 6. Multitemporal analysis by fluvial flooding in front of Cáhuil. The 1987's photograph corresponds to the date in which the condition of high soil humidity is clearest observed, since it is detected four zones with very dark reflectance (red dashed lines) smoothly clearest than the estuary, representative of a sheet of water or soils highly wet. The maximum lateral width of this humidity condition reaches approximately $110 \mathrm{~m}$ just in the central zone of the coastal plain (Te); whereas, the minimum width reaches $40 \mathrm{~m}$ near of the current Cáhuil's bridge. Similar patterns of reflectance and texture are detected in the aerial photographs of 1994 and 1997. 
y 2010, en lo referente a la dinámica endógena. En consecuencia se identifican sectores afectados por una condición de multiamenazas debido a la cercanía a la línea de costa y según la dinámica de la unidad geomorfológica que corresponda. En el litoral entre Punta de Lobos y Cáhuil es posible caracterizarlo con multiamenazas debido a la ocurrencia de inundaciones por tsunamis y marejadas, como también por problemas de drenaje del suelo, junto a erosión de suelo en las laderas de las terrazas marinas. En la zona sur, Cahuil, existe una condición de proximidad y superposición de multiamenazas derivadas de la inundación por tsunami y desborde de cauces naturales, licuefacción de suelos y desprendimientos de rocas, siendo la Terraza estuarial la unidad geomorfológica más inestable, debido a la susceptibilidad a inundaciones por tsunamis, desborde del cauce por las crecidas del Estero Nilahue y licuefacción de suelo.
Desde el punto de vista de la acción de los procesos analizados, las unidades geomorfológicas presentan actividad debido a la ocurrencia de eventos pluviométricos intensos y esporádicos, cuando se trata de la dinámica subaérea, como también a sismos de gran magnitud, evidenciado por los efectos de los terremotos de 1985 y 2010, en lo referente a la dinámica endógena. En consecuencia se identifican sectores afectados por una condición de multiamenazas por la cercanía a la línea de costa y por la dinámica de la unidad geomorfológica que corresponda. En el litoral entre Punta de Lobos y Cáhuil también es zona de multiamenazas debido a la ocurrencia de inundaciones por tsunamis y marejadas, como también por problemas de drenaje del suelo, junto a erosión de suelo en las laderas de las terrazas marinas. En la zona sur, Cahuil, existe una condición de proximidad y superposición de amenazas derivadas de la inundación por

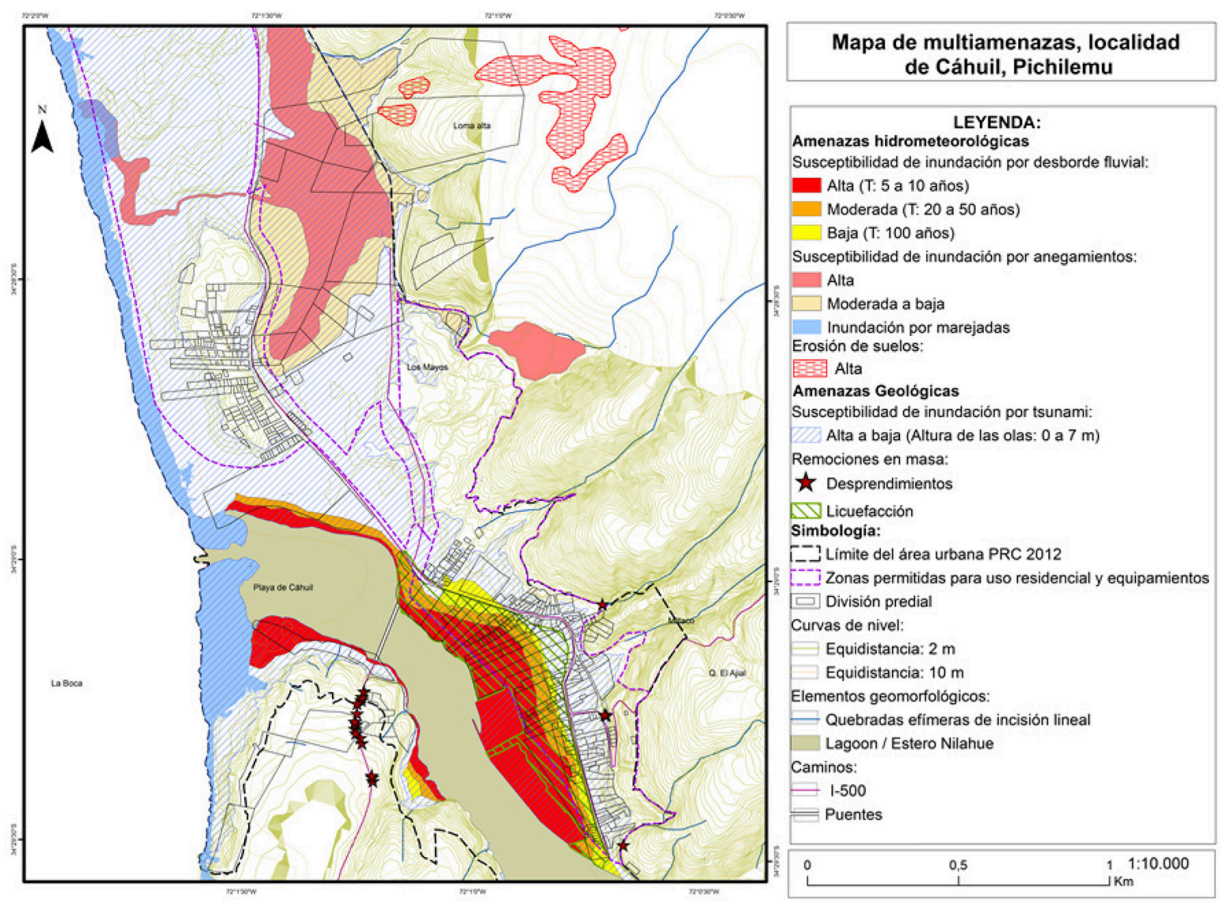

Fig. 7. Mapa de Multiamenazas, Cáhuil.

Fig. 7. Multihazards map, Cáhuil. 
tsunami y desborde de cauces naturales, licuefacción de suelos y desprendimientos de rocas, siendo la Terraza estuarial la unidad geomorfológica más inestable, debido a la susceptibilidad a inundaciones por tsunamis, desborde del cauce por las crecidas del Estero Nilahue y licuefacción de suelo.

Las amenazas de origen hidrometeorológicas identificadas tiene un impacto territorial relevante en la medida que los umbrales de precipitación y sus períodos de retorno son de una baja frecuencia, superados con eventos pluviométricos cuyos montos oscilan entre 65 y $77 \mathrm{~mm}$ concentrados en $24 \mathrm{hrs}$, que tienen un período de retorno de 4-6 años, respectivamente. Estos umbrales tienen un efecto sinérgico en la susceptibilidad de amenazas por erosión de suelos y probablemente en las remociones en masa. En el caso de las inundaciones por desborde de cauces, los caudales más peligrosos para la infraestructura y las alturas de agua asociadas, presentan períodos de retorno superiores a 50 años, intervalo de tiempo que tampoco puede considerarse excluyente para el caso de las inundaciones por mal drenaje del suelo.

Analizando la zonificación de multiamenazas de la figura 7 , predominan territorialmente las áreas sujetas a amenazas de jerarquía alta en el área de expansión urbana de Cáhuil, ya sea en la parte del Estero Nilahue, cuyos habitantes son originarios de la zona, como también en el borde costero, con viviendas destinadas a segundas residencias de turismo de playa, es decir, población flotante estacional.

Es importante destacar la incorporación de las dunas costera como sector habilitado para el poblamiento urbano, que además es un una zona de amenazas de tsunamis. Otro hecho relevante es la vulnerabilidad de la única vía de conexión vial hacia Pichilemu y Bucalemu, al Norte y Sur de Cáhuil respectivamente, construida en la terraza de abrasión marina y sujeta a procesos de desprendimientos de rocas.

\section{CONCLUSIONES}

Del análisis de los datos y de la cartografía especialmente generada se concluye que existen condiciones geomorfológicas e hidrometeorológicas que configuran escenarios actuales y potenciales de multiamenazas en la zona de estudio, que además está en proceso de expansión urbana. Se ha estimado que solo un 39\% del área propuesta con uso urbano residencial y de equipamiento no se encuentra expuesta a amenazas. Se concluye además un escenario de construcción de riesgos asociados a las multiamenazas, inherentes a una zona litoral-fluvial sismo tectónicamente activa.

Se evidencia de manera indirecta una presión sobre el territorio y por ende en sus recursos naturales. Es un territorio con distintos grados de intervención, toda vez que el rol antrópico ha dinamizado y condicionado la presencia de amenazas por erosión de suelos, licuefacción y remociones en masa. Existe un conjunto de unidades morfodinámicas sujetas a procesos de inestabilidad que explican una condición de amenaza global derivada de la susceptibilidad de coalescencia espacial, pero no necesariamente temporal, de múltiples amenazas de origen natural.

En consecuencia se concluye también que a mediano plazo existirá un aumento de la condición de riesgo debido a la mayor exposición que ha generado la proyección del área urbana sobre campos de dunas próximos al borde costero, que son susceptibles a presentar amenazas de inundación por tsunami y marejadas, como también en las riberas del Estero Nilahue, vulnerable a las crecidas e inundaciones.

\section{AGRADECIMIENTOS}

Proyecto FONDECYT 1100223. 


\section{REFERENCIAS}

ALCÁNTARA, I., 2002. Geomorphology, natural hazards, vulnerability and prevention of natural disasters in developing countries. Geomorphology, 47: 107-124.

ANDRADE, B. \& S. GRAU, 2005. La laguna de Cáhuil, un ejemplo de estuario estacional en Chile central. Revista de Geografía Norte Grande, 33: 59-72.

ARAYA-VERGARA, J.F. \& R. BORGUEL, 1972. El uso de la carta 1:50.000 del Instituto Geográfico Militar en la confección de unidades Geográficofísicas. Primer Simposium Cartográfico Nacional, Instituto Geográfico Nacional, 1: 263-269.

ARAYA-VERGARA, J.F., 2003. Génesis de la ensenada en zeta de Pichilemu, Chile Central. Investigaciones Geográficas, 37: 41-65.

ARNAUD-FASSETTA, G., E. COSSART \& M. FORT, 2005. Hydro-geomorphic hazards and impact of man-made structures during the catastrophic flood of June 2000 in the Upper Guil catchment (Queyras, Southern French Alps). Geomorphology, 66: 41-67.

BANKS, J.C., J.V. CAMP \& M. D. MANKOWITZ, 2014. Adaptation planning for floods: a review of available tools. Natural Hazards, 70: 1327-1337.

BLAIKE, P., T. CANNON, T. DAVIS \& B. WISNER, 2003. At Risk, Natural hazards people's vulnerability and disaster. London: Routledge.

BRUNSDEN, D. \& J. B. THORNES, 1979. Landscape sensitivity and change. Transactions of the Institute of British Geographers, 4:463-484.
CARDONA, O.D., 1999. Environmental Management and Disaster Prevention: Two Related Topics - A Holistic Risk Assessment and Management Approach, Natural Disaster management, Ingleton J. (Ed.) IDNDR, Tudor Rose, IDNDR, London.

CASTRO, C. P., I. IBARRA, M. LUKAS \& J. P. SARMIENTO, 2015. Disaster risk construction in the progressive consolidation of informal settlements: Iquique and Puerto Montt (Chile) case studied. International Journal of Disaster Risks Reduction, 13: 109-127.

CECIONI, A. \& V. PINEDA, 2009. Geology and Geomorphology of Natural Hazards and Humand-Induced Disasters in Chile. In: Latrubesse, E. (Ed.), Elsevier, pp. 379-412. Amsterdam. 550 pp.

\section{D'ERCOLE, R., P. PIGEON \&} T. SERRANO, 2009. Complejidad, incertidumbre y vulnerabilidad: el riesgo asociado al volcán Cotopaxi en el Valle de los Chillos (Quito, Ecuador). Bulletin de I'Institut Francaise d'Etudes Andines, 38(3): 709-733.

DÍEZ-HERRERO, A., P. FREDI, E. PALMIERI \& R. MARINIR, 2008. Mapas de peligrosidad por avenidas e inundaciones. Guía metodológica para su elaboración. Madrid: Instituto Geológico y Minero de España, Serie Riesgos Geológicos/Geotecnia n ${ }^{\mathrm{o}} 1.190$ pp.

\section{FEDERAL}

EMERGENCY

MANAGEMENT AGENCY (FEMA), 2009. Mapping the zone: Improving flood map accuracy. Washington D.C. The National Academy Press, 122p.

FOOKES, P., E. LEE \& J. GRIFFITHS, 2007. Engineering Geomorphology, Theory and Practice. Scotland: Whittles Publishing. $307 \mathrm{pp}$. 
GUMBEL, E.J., 2004. Statistics of Extremes. New York: Columbia Univeristy Press. 400 pp.

GURNELL, A., J. PEIRY \& A. PETTS, 2003. Using Historical data in Fluvial Geomorphology. En: Kondolf, G., Piegay, $\mathrm{H}$. Tools in fluvial geomorphology. Sussex, John Wiley \& Sons Ltda. 679p.

HERNÁNDEZ, J. \& V. FRANCO, 1999. Hidráulica de canales: capítulo 5 del Manual de ingeniería de ríos. México D.F., Universidad Autónoma de México (UNAM), Instituto de Ingeniería. 207p.

IBARRA, C., 2013. Geomorfología aplicada en la evaluación y análisis de amenazas naturales en la zona sur de la comuna de Pichilemu: sectores de Punta de Lobos-Cáhuil-Estero Nilahue. VI Región, Chile. Santiago de Chile: Memoria para optar al título profesional de Geógrafo, Universidad de Chile. Inédito.

ILUSTRE MUNICIPALIDAD DE PICHILEMU, 2004. Plan Regulador Comunal de Pichilemu. Chile. 190 p.

ILUSTRE MUNICIPALIDAD DE PICHILEMU, 2012. Estudio de Modificación del Plan Regulador Comunal de Pichilemu. Chile. 91 p.

JENN, F., K. KNÖDEL, M. LIESE \& H. JÜRGEN, 2007. Infiltration. En: Environmental geology. KNÖDEL, K., LANGE, G., JÜRGEN, H. (Eds.) Alemania, Hannover. Springer: 603-619.

KAPPES, M.S., K. GRUBER, S. FRIGERIO, R. BELL, M. KEILER \& T. GLADE, 2012. The MultiRISK platform: The technical concept and application of a regional-scale multihazard exposure analysis tool. Geomorphology, 151-152: 139-155.
KEILER, M., A. KELLERERPIRKLBAUER \& J.C. OTTO, 2012. Concepts and implications of environmental change and human impact: Studies from Austrian geomorphological research (Preface). Geogranna, 94: 1-5.

KNODEL, K., F. JENN, M. LIESE \& H. JURGEN, 2007. Runoff. I: Environmental Geology: Handbook of field Methods and case studies. KNODEL, K., LANGE, G, VOIGHT, H (Eds.). New York, Springer.

LAVELL, A. \& E. FRANCO, 1996. Estado, Sociedad y Gestión de Desastres: en busca del paradigma perdido. Lavell y Franco, Editores. LA RED, Red de Estudios Sociales en Prevención de Desastres en América Latina, ITDG. Perú.

LAVELL, A., 2004. The Lower Lempa River Valley, El Salvador: Risk Reduction and Development Project. Bankoff, G., G. Frerks y Dorothea Hilhorst, Mapping Vulnerability: Disasters, Development and People. Earthscan. Londres.

LEI, Y. \& J. WANG, 2014. A preliminary discussion on the opportunities and challenges of linking climatic change adaptation with disaster risk reduction. Natural Hazards, 71(3): 1587-1597.

MARDONES, M. \& C. VIDAL, 2004. La zonificación y evaluación de los riesgos naturales de tipo geomorfológico: un instrumento para la planificación urbana en la ciudad de Concepción. Revista EURE, 27 (81): 97-122.

MINISTERIO DE OBRAS PÚBLICAS (MOP) \& DIRECCIÓN GENERAL DE AGUAS (DGA), 1995. Manual de cálculo de crecidas y caudales mínimos en cuencas sin información fluviométrica. Santiago: MOP-DGA. 147 pp. 
PANIZZA, M., 1996. Environmental geomorphology. Developments in earth surface processes (vol.4). Amsterdam, Elsevier, 268 pp.

PEÑA-MONNÉ, J. L., 1997. Cartografía geomorfológica básica y aplicada. Logroño: Geoforma ediciones. 227pp.

PELLING, M., 2003. Natural disasters and development in a globalizing world. London; New York: Routledge.

PELling, M. \& B. WISNER, 2008. Disaster Risk Reduction. Case from urban Africa. MP Books, Bodmin.

\section{PONTIFICIA}

UNIVERSIDAD

CATÓliCA DE CHILE (PUC), 2010. Estudio de fundado de riesgos. Modificación Plan Regulador Comunal de Pichilemu. Santiago: SUBDERE-PUC. 28 pp.

QUEZADA, J., E. JAQUE, A. BELMONTE， F. FERNÁNDEZ， D. VÁSQUEZ \& C. MARTÍNEZ, 2010. Movimientos cosísmicos verticales y cambios geomorfológicos generados durante el terremoto de $\mathrm{Mw}=8,8$ del $27 \mathrm{de}$ febrero del 2010 en el centro sur de Chile. Revista Geográfica del Sur, 2:11-45.

SAHIR, O. \& S. MOHAMED, 2014. Coastal vulnerability to sea-level rise: a spatial-temporal assessment framework. Natural Hazards, 70: 395-414.

SARMIENTO, J.P., G. HOBERMAN, M. ILCHEVA, A. ASGARY, A. MAJANO, S. POGGIONE \& L. DURAN, 2015 Private sector and disaster risk reduction: The Cases of Bogota, Miami, Kingston, San Jose, Santiago, and Vancouver. International Journal of Disaster Risk Reduction, 14: 255-237.
SELBY, M. J., 1993. Hillslope Materials and Processes. 2ed. Oxford: Oxford University Press. 451 pp.

\section{SERVICIONACIONALDE GEOLOGÍA Y MINERÍA (SERNAGEOMIN),} 2010. Efectos geológicos del sismo del 27 de febrero de 2010: observaciones de reconstrucción y depósitos de tsunami en la comuna de Pichilemu, VI Región de O'Higgins. [INF.O'Higgins-02]. SERNAGEOMIN: 2p. Santiago.

SMITH, M.I., P. PARON \& J. GRIFFITHS, 2011. Geomorphological mapping: methods and applications. Amsterdam: Elsevier. 606pp.

\section{SOIL CONSERVATION SERVICE} (S.C.S.), 1972. National Engineering Handbook, Section 4, Hydrology. US 444. Department of Agriculture, US Government Printing Office, Washington, DC.

SOTO, M.V. \& R. MORENO, 2011. Implicancias del crecimiento urbano en el piedmont andino de Santiago: un tema de sustentabilidad urbana. Chile. In: Sobre la Medición de la forma del espacio urbano: aplicación a Santiago (Chile) y Zaragoza (España). Severino Escolano y Jorge Ortiz (Eds.) Ministerio de asuntos Exteriores y de Cooperación/AECID: 237-255.

SOTO, M.V., J. ARRIAGADA, C. P. CASTRO-CORREO, I. IBARRA \& G. RODOLFI, 2015. Geodynamic conditions resulting from the earthquake and tsunami of 2010 on the coast of central Chile. The case of Pichilemu. Revista de Geografia Norte Grande, 60: 79-95.

SOTO, M.V., M. MÄRKER, J. ARRIAGADA, C. P. CASTRO \& J. RODOLFI, 2010. Evaluación de la amenaza natural en ambiente semiárido, sustentada en la geomorfología y el modelamiento de índices topográficos. 
Salamanca, Región de Coquimbo, Chile. Revista Investigaciones Geográficas, 42: 19-36.

WILCOX, D.P., M.G. SORICE \& M.H. YOUNG, 2011. Dryland ecohydrology in the anthopocene: taking stock of human -ecological interactions. Geography Compass, 5: 112-127.
WITHING, P., 2003. Flow Measurement and Characterization. In: Tools in fluvial geomorphology. KONDOLF, G., PIÉGAY, H. (Ed.). Sussex, John Wiley \& Sons Ltda. 679 p. 